\title{
Does anti-VEGF bevacizumab improve survival in experimental sepsis?
}

\author{
Emmanuel Besnier ${ }^{1,2^{*}}$ (D) Ebba Brakenhielm ${ }^{1}$, Vincent Richard ${ }^{1}$ and Fabienne Tamion ${ }^{1,3}$ \\ See related research by Jeong et al. https://ccforum.biomedcentral.com/articles/10.1186/cc12742
}

In a previous issue of Critical Care, Jeong et al. reported a beneficial effect of bevacizumab (Bev), the first humanized vascular endothelial growth factor (VEGF)-neutralizing antibody, on vascular permeability and mortality in a murine model of sepsis [1]. VEGF has been associated with mortality during sepsis [2], and the administration of its natural antagonist improved survival in experimental sepsis [3]. Jeong et al. demonstrated that Bev reduced mortality in sepsis induced either by cecal ligature puncture (CLP) or by endotoxemia. Despite promising experimental data, no other study has yet confirmed these results. A clinical study was planned to evaluate Bev administration in critically ill patients but it was withdrawn before enrolment (NCT01063010).

Thus, we aimed to reassess the potential benefit of Bev during experimental sepsis. After approval by the HauteNormandie ethics committee (number 8092), male C57Bl6 mice received intraperitoneal $\mathrm{NaCl}$ (control) or $\operatorname{Bev}(0.5 \mathrm{mg} / \mathrm{kg})$ immediately before CLP ( $n=15 /$ group), performed as described previously [4]. Briefly, the cecum was ligated (75\% of total length) and punctioned bilaterally with a $21 \mathrm{G}$ needle. Topical lidocaïne (2\%) was applied and mice received a sub-cutaneous administration of the antibiotic ofloxacine $(30 \mathrm{mg} / \mathrm{kg})$, the analgesic tramadol $(40 \mathrm{mg} / \mathrm{kg})$, and $\mathrm{NaCl}(30 \mathrm{ml} / \mathrm{kg})$. Survival was evaluated twice per day for 10 days and analyzed through a log-rank test.

No significant difference in mortality was observed between the Bev and control groups (36 versus $27 \%$ at day $10, p=0.64)$. To overcome any non-optimal effect linked to the route of administration, and also to better mimic clinical use, we repeated the experiments with intravenous injection of Bev before surgery $(n=8 /$ group). Again, we did not observe any effect on mortality compared to CLP controls (42 versus $37 \%$ at day 10 , $p=0.74$ ). Pooling the data between experiments (Bev treatment either IP or IV versus controls; $n=23$ /group) also did not show any statistical difference (38 versus $31 \%, p=0.56$; Fig. 1 ).

Even if our experimental procedure slightly varies, notably regarding the severity of sepsis, with a larger puncture site, and the use of intravenous route in some of the mice, these results contradict those described by Jeong et al. The absence of replication of their results may be surprising, notably regarding the suspected effects of the VEGF pathways in sepsis. Although we cannot identify the origin of this contradiction, the absence of new publications on this topic, in association with our negative results, raises the question of the clinical rational of antiVEGF treatment in septic patients.

\footnotetext{
* Correspondence: emmanuel.besnier@chu-rouen.fr

${ }^{1}$ Normandie Univ, UNIROUEN, INSERM U1096, 76000 Rouen, France

${ }^{2}$ Department of Anaesthesia and Critical Care, Rouen University Hospital,

76000 Rouen, France

Full list of author information is available at the end of the article
} 


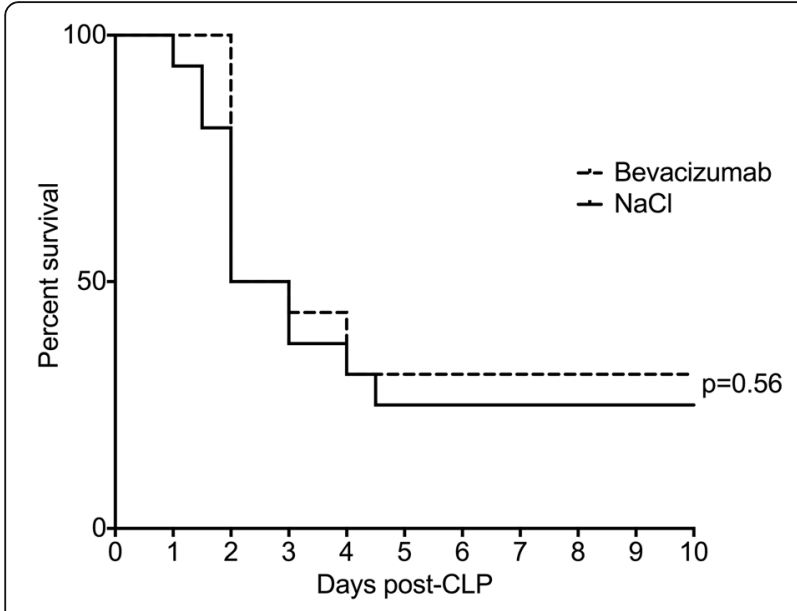

Fig. 1 Survival of septic mice treated with bevacizumab or $\mathrm{NaCl}$ over a ten days period

\section{Abbreviations}

Bev: Bevacizumab; CLP: Caecal ligation and puncture; VEGF: Vascular endothelial growth factor

\section{Acknowledgements}

Not applicable.

\section{Funding}

Funding by the French national institute for research (INSERM).

\section{Availability of data and materials}

The datasets used and/or analyzed during the current study are available from the corresponding author on reasonable request.

\section{Authors' contributions}

EBe: experimentation, writing of manuscript. Ebr: study design. VR: reviewing. FT: supervising. All authors read and approved the final manuscript.

\section{Competing interests}

The authors declare that they have no competing interests.

\section{Consent for publication}

Not applicable.

\section{Ethics approval and consent to participate}

All experiments were realized in accordance with the European directive 2010/63/EU and were approved by the Haute-Normandie ethic committee (approval number 8092).

\section{Publisher's Note}

Springer Nature remains neutral with regard to jurisdictional claims in published maps and institutional affiliations.

\section{Author details}

'Normandie Univ, UNIROUEN, INSERM U1096, 76000 Rouen, France. 2Department of Anaesthesia and Critical Care, Rouen University Hospital, 76000 Rouen, France. ${ }^{3}$ Medical Critical Care Unit, Rouen University Hospital, 76000 Rouen, France.

Published online: 05 July 2017

\section{References}

1. Jeong SJ, Han SH, Kim CO, Choi JY, Kim JM. Anti-vascular endothelial growth factor antibody attenuates inflammation and decreases mortality in an experimental model of severe sepsis. Crit Care. 2013;17:R97.
2. Shapiro NI, Yano K, Okada H, Fischer C, Howell M, Spokes KC, et al. A prospective, observational study of soluble FLT-1 and vascular endothelial growth factor in sepsis. Shock. 2008;29:452-7.

3. Tsao PN, Chan FT, Wei SC, Hsieh WS, Chou HC, Su YN, et al. Soluble vascular endothelial growth factor receptor-1 protects mice in sepsis. Crit Care Med. 2007;35:1955-60.

4. Toscano MG, Ganea D, Gamero AM. Cecal ligation puncture procedure. J Vis Exp JoVE. 2011;51:e2860 